\title{
Graphitic Carbon Nitrides Supported by Nitrogen-Doped Graphene as Efficient Metal-Free Electrocatalysts for Oxygen Reduction
}

\author{
Min Wang, Zhanpeng $\mathrm{Wu}^{\dagger}$, Liming Dai* \\ Department of Macromolecular Science and Engineering, Case Western Reserve University, \\ Cleveland, $\mathrm{OH} 44106$, USA \\ ${ }^{\dagger}$ On leave of absence from Materials Science and Engineering, Beijing University of Chemical \\ Technology Beijing 100029, China \\ *Corresponding author, Tel: +1 (216) 3684176; Fax: +1 (216) 3684202. \\ E-mail: liming.dai@ case.edu
}

\begin{abstract}
:
Owing to its low cost and rich nitrogen content, graphitic carbon nitride $\left(\mathrm{g}-\mathrm{C}_{3} \mathrm{~N}_{4}\right)$ is promising metal-free catalyst for oxygen reduction reaction (ORR). However, the electrocatalytic performance of carbon nitride is limited by its low conductivity. In order to circumference this limitation, we incorporated $\mathrm{g}-\mathrm{C}_{3} \mathrm{~N}_{4}$ with nitrogen-doped graphene (N-G) by ball-milling $\mathrm{g}-\mathrm{C}_{3} \mathrm{~N}_{4}$ and $\mathrm{N}-\mathrm{G}$ to produce $\mathrm{g}-\mathrm{C}_{3} \mathrm{~N}_{4} @ \mathrm{~N}-\mathrm{G}$ of an ORR catalytic activity comparable to the commercial Pt/C catalyst, along with a better long-term stability and more tolerance to the methanol crossover effect.
\end{abstract}

Keywords: carbon nitride, graphene, metal-free catalyst, oxygen reduction, ball milling

\section{Introduction}

Instead of burning fossil fuels, fuel cells can convert chemical energy directly into electricity by reducing oxygen gas at cathode and oxidizing hydrogen gas at anode with water as the only by-product and free from pollution. Due to the slow kinetics of the oxygen reduction reaction (ORR), catalysts are required for ORR. Platinum (Pt) has been known to be the best electrocatalyst for the cathodic oxygen reduction. However, commercial Pt/C catalysts are still 
suffered from multiple drawbacks, including their high cost, limited reserve, sluggish kinetics, and susceptible to the methanol crossover/CO poisoning effect. Therefore, it is highly desirable to develop new low-cost, high-performance ORR catalysts to reduce/replace the commercial $\mathrm{Pt} / \mathrm{C}$ catalysts for practical applications [1].

We have previously demonstrated that heteroatom-doped carbon materials could act as metal-free catalysts with superb ORR activities. Examples include N-doped carbon nanotubes [2, 3], N-doped graphene (N-G) [4], BCN graphene [5], and N, P co-doped VACNTs [6]. Among them, nitrogen-doping has been demonstrated to be most effective to improve the ORR electrocatalytic activities of carbon nanomaterials. In this regard, carbon nitrides with a high nitrogen content is very promising metal-free electrocatalysts. Carbon nitrides have different crystal structures, including tetrahedral carbon nitride $\left(\mathrm{b}-\mathrm{C}_{3} \mathrm{~N}_{4}\right)$ and graphitic carbon nitride (g$\mathrm{C}_{3} \mathrm{~N}_{4}$ ). b- $\mathrm{C}_{3} \mathrm{~N}_{4}$ is predicted to possess a high hardness and low compressibility similar as diamond while $\mathrm{g}-\mathrm{C}_{3} \mathrm{~N}_{4}$ is regarded as the most stable allotrope at ambient conditions [7]. For g$\mathrm{C}_{3} \mathrm{~N}_{4}$, two structural isomers have been identified: one comprises condensed melamine units containing a periodic array of single carbon vacancies; the other is made up of condensed melem (2,5,8,-triamino-tri-s-triazine) subunits containing larger periodic vacancies in the lattice [8]. Recently, carbon nitrides have been proved to be effective catalysts for water splitting under visible light [9], splitting of $\mathrm{CO}_{2}$ [10], and cyclotrimerization of various nitriles [11]. However, the electrocatalytic performance of carbon nitride for ORR was found to be very poor due to its low conductivity [8]. In order to improve the electrocatalytic activity of $\mathrm{g}-\mathrm{C}_{3} \mathrm{~N}_{4}$, various carbon materials have been used as the support to enhance charge-transfer, and hence the catalytic performance of $\mathrm{g}-\mathrm{C}_{3} \mathrm{~N}_{4}$. Examples include the combined $\mathrm{g}-\mathrm{C}_{3} \mathrm{~N}_{4}$ and carbon black [8,12], g- $\mathrm{C}_{3} \mathrm{~N}_{4}$ immobilized graphene sheets [13-15], $\mathrm{g}-\mathrm{C}_{3} \mathrm{~N}_{4}$ incorporated mesoporous carbon (CMK-3) [16, 
17], and $3 \mathrm{D}$ ordered macroporous $\mathrm{g}-\mathrm{C}_{3} \mathrm{~N}_{4} / \mathrm{C}$ [19]. Of particular interest, $\mathrm{N}-\mathrm{G}$ is a promising candidate for supporting carbon nitride to enhance the electron transfer, though yet reported.

In collaboration, we have previously used ball milling technique for low-cost, scalable production of various edge-functionalized graphene materials, including nitrogen-edge-doped graphene, as metal-free electrocatalysts for oxygen reduction [20-23]. Herein, we report new metal-free ORR electrocatalysts based on $\mathrm{N}-\mathrm{G}$ and $\mathrm{g}-\mathrm{C}_{3} \mathrm{~N}_{4}$ hybrid materials $\left(\mathrm{g}-\mathrm{C}_{3} \mathrm{~N}_{4} @ \mathrm{~N}-\mathrm{G}\right)$ produced by ball milling $\mathrm{g}-\mathrm{C}_{3} \mathrm{~N}_{4}$ prepared from pyrolysis of cyanamide under a flow of argon gas and N-doped graphene from modified Hummer's method.

\section{Experimental section}

\subsection{Synthesis of graphitic carbon nitride from cyanamide}

The graphitic carbon nitride was prepared by pyrolysis of cyanamide under a flow of argon gas. In a typical experiment, the cyanamide precursor was placed into a quartz boat, which was then inset into a quartz tube in a muffle furnace. Thereafter, the quartz tube was gradually heated up to $550^{\circ} \mathrm{C}$ within 2 hours and kept at $550^{\circ} \mathrm{C}$ for additional 4 hours under the flow of argon gas (200 sccm), followed by air cooling down to room temperature whilst kept the argon flowing through inside of the quartz tube. $[18,19]$

\subsection{Preparation of graphene oxide}

Graphene oxide was prepared using the modified Hummers' method [24]. Typically, graphite powder $(3.0 \mathrm{~g})$ was added into a mixture solution of concentrated $\mathrm{H}_{2} \mathrm{SO}_{4}(70 \mathrm{~mL})$ and $\mathrm{NaNO}_{3}$ $(1.5 \mathrm{~g})$ in an ice bath. To the resulting mixture, $\mathrm{KMnO}_{4}(9.0 \mathrm{~g})$ was added slowly, followed by stirring at $35^{\circ} \mathrm{C}$ for 2 hours. Then the newly-produced mixture was added into deionized water (150 mL) slowly, which was poured into $500 \mathrm{~mL}$ deionized water containing $15 \mathrm{~mL} 30 \% \mathrm{H}_{2} \mathrm{O}_{2}$. 
After filtration, the solid component was recovered from the mixture and washed by $\mathrm{HCl}(10$ wt.\%) and deionized water. The resultant solid was then added into water and sonicated for 1 hour for exfoliation of graphene oxide. The graphene oxide dispersion thus produced was then centrifuged at $4000 \mathrm{rpm}$ for $20 \mathrm{~min}$, and the graphene oxide was recovered by filtration $(0.45 \mu \mathrm{m}$ Millipore PVDF membrane) of the supernatant and vacuum drying (10 mTorr, $25^{\circ} \mathrm{C}$ for $72 \mathrm{~h}$ ). Alternatively, the graphene oxide solution was freeze-dried according to published procedures (typically, freeze-drying at 10 mTorr for 3 days) [25].

\subsection{Preparation of nitrogen-doped graphene}

Following our previous work [26], we prepared nitrogen-doped graphene by annealing the freeze-dried graphene oxide in a quartz tube furnace under ammonia/argon gas mixture $\left(\mathrm{NH}_{3}\right.$ : $\mathrm{Ar}$ $=1: 1 \mathrm{v} / \mathrm{v}, 200 \mathrm{sccm})$ at $800^{\circ} \mathrm{C}$ for 1 hour.

\subsection{Preparation of $g-C_{3} N_{4} @ N-G$ and $g-C_{3} N_{4} \& N-G$ mixture}

g- $\mathrm{C}_{3} \mathrm{~N}_{4} @ \mathrm{~N}-\mathrm{G}$ was prepared by ball milling g- $\mathrm{C}_{3} \mathrm{~N}_{4}$ and $\mathrm{N}-\mathrm{G}(1: 3 \mathrm{wt} / \mathrm{wt})$. Briefly, g- $\mathrm{C}_{3} \mathrm{~N}_{4}(10$ mg) was first dispersed in $20 \mathrm{~mL}$ DI-water and sonicated for $20 \mathrm{~min}$, which was placed together with N-G (30 mg) into a stainless steel container with $100 \mathrm{~g}$ stainless steel balls of 5-mm in diameter. The container was then fixed in a planetary ball-mill machine and agitated with 500 rpm for $24 \mathrm{~h}$. The resultant product was washed with $\mathrm{HCl}(10 \mathrm{wt} . \%)$ to remove metal impurities, if any, and then collected by filtration and vacuum drying. $\mathrm{g}-\mathrm{C}_{3} \mathrm{~N}_{4} \& \mathrm{~N}-\mathrm{G}$ mixture was prepared simply by mixing $10 \mathrm{mg}$ g- $\mathrm{C}_{3} \mathrm{~N}_{4}$ and $30 \mathrm{mg} \mathrm{N}-\mathrm{G}$ in $20 \mathrm{~mL}$ DI-water under stirring for $24 \mathrm{~h}$, followed by filtration and vacuum drying.

\subsection{Structure characterization}


Transmission electron microscopic (TEM) images were taken using a JEOL2100 high resolution transmission electron microscope operating at an acceleration voltage of $200 \mathrm{kV}$. Xray diffraction (XRD) was carried out on a Miniflex Desktop X-ray Diffractometer while X-ray photoelectron spectroscopy (XPS) was conducted on VG Microtech ESCA 2000 using a monochromic Al X-ray source $(97.9 \mathrm{~W}, 1486.6 \mathrm{eV})$. Raman spectra were collected on a Raman spectrometer (Renishaw) using $514 \mathrm{~nm}$ laser. Thermogravimetric analysis (TGA) was performed on a TA instrument (Q50) with a heating rate of $10{ }^{\circ} \mathrm{C} / \mathrm{min}$ in air.

\subsection{Electrochemical characterization}

Electrochemical measurements were performed on an electrochemical workstation (CHI760C, $\mathrm{CH}$ Instrument) in a three-electrode electrochemical cell at room temperature. A platinum wire was used as the counter electrode, and a saturated calomel electrode (SCE) was used as the reference electrode. The catalyst with a loading amount of $200 \mu \mathrm{g} / \mathrm{cm}^{2}$ was drop-cast onto the glass carbon electrode $(\mathrm{CH}$ Instrument, $\mathrm{d}=0.5 \mathrm{~cm})$, followed by casting with $10 \mu \mathrm{L}$ Nafion solution ( $0.05 \mathrm{wt} \%$ in ethanol) as the binder. Catalytic activities of the electrocatalysts were evaluated by cyclic voltammetry $(\mathrm{CV})$ and linear sweep voltammetry (LSV) techniques on rotating disk electrodes (RDEs) in an oxygen saturated aqueous solution of $0.1 \mathrm{M} \mathrm{KOH}$ at room temperature.

\section{Results and discussion}

Fig. 1(a) shows a typical TEM image of the $\mathrm{g}-\mathrm{C}_{3} \mathrm{~N}_{4}$ while Fig. 1(b) reproduces a TEM image for the wrinkled N-G sheets. The TEM image for the ball-milled $\mathrm{g}-\mathrm{C}_{3} \mathrm{~N}_{4} @ \mathrm{~N}-\mathrm{G}$ is given in Fig. 1(c), which shows that the $\mathrm{g}-\mathrm{C}_{3} \mathrm{~N}_{4}$ nanosheets were uniformly distributed on the $\mathrm{N}-\mathrm{G}$ sheets with an intimate contact between them - an advantage for conductivity enhancement of the $\mathrm{g}-\mathrm{C}_{3} \mathrm{~N}_{4}$ 
nanosheets, and hence their electrocatalytic activities. A comparison of Fig. 1(a) with Fig. 1(c) shows that the $\mathrm{g}-\mathrm{C}_{3} \mathrm{~N}_{4}$ sheets were mechanically cracked into smaller nanosheets and then deposited onto the $\mathrm{N}-\mathrm{G}$ sheets during the ball milling process.

Fig. 2(a) shows the $X$-ray diffraction (XRD) patterns for $g-C_{3} N_{4}, N-G$ and $g-C_{3} N_{4} @ N-G$. As expected, g- $\mathrm{C}_{3} \mathrm{~N}_{4}$ shows a strong peak at $27.4^{\circ}$, corresponding to the in-plane ordering of tri-striazine units [27]. The interlayer-stacking peak around $13.0^{\circ}$ [27] is largely absent, indicating the lack of a through-thickness order. The N-G shows a relatively broad peak at around $26.2^{\circ}$ characteristic of graphitic carbons while $\mathrm{g}-\mathrm{C}_{3} \mathrm{~N}_{4} @ \mathrm{~N}-\mathrm{G}$ shows a similar peak at around $26.4^{\circ}$ with a slight up-shift. This, together with the appearance of a broad band, albeit very weak, centered around $13^{\circ}$, indicates the successful deposition of $\mathrm{g}-\mathrm{C}_{3} \mathrm{~N}_{4}$ onto the graphene sheets to restore the through-thickness order to a certain degree. The structural order of $\mathrm{g}-\mathrm{C}_{3} \mathrm{~N}_{4} @ \mathrm{~N}-\mathrm{G}$ was further investigated using Raman spectroscopy with respect to N-G. As can be seen in Fig. 2(b), a Dband at around $1356 \mathrm{~cm}^{-1}$ and G-band at around $1588 \mathrm{~cm}^{-1}$ were observed for both N-G and g$\mathrm{C}_{3} \mathrm{~N}_{4} @ \mathrm{~N}-\mathrm{G}$. The peak intensity ratio of the D-band to G-band $\left(\mathrm{I}_{\mathrm{D}} / \mathrm{I}_{\mathrm{G}}\right)$ was estimated to be about 0.94 and 0.99 for $\mathrm{N}-\mathrm{G}$ and $\mathrm{g}-\mathrm{C}_{3} \mathrm{~N}_{4} @ \mathrm{~N}-\mathrm{G}$, respectively. The observed increase in the $\mathrm{I}_{\mathrm{D}} / \mathrm{I}_{\mathrm{G}}$ ratio indicates that more defects were introduced on the graphene basal plane due to the deposition of g- $\mathrm{C}_{3} \mathrm{~N}_{4}$ nanosheets - an additional advantage for electrocatalysis. Thermogravimetric analysis (TGA) was employed to investigate the thermo stability of $\mathrm{g}-\mathrm{C}_{3} \mathrm{~N}_{4} @ \mathrm{~N}-\mathrm{G}$ and its constituent components (i.e., g- $\mathrm{C}_{3} \mathrm{~N}_{4}, \mathrm{~N}-\mathrm{G}$ ). As seen in Fig. 2(c), g- $\mathrm{C}_{3} \mathrm{~N}_{4}$ exhibited a decomposition temperature at around $650{ }^{\circ} \mathrm{C}$ whereas the $\mathrm{N}-\mathrm{G}$ and $\mathrm{g}-\mathrm{C}_{3} \mathrm{~N}_{4} @ \mathrm{~N}-\mathrm{G}$ decomposed at a lower temperature $\left(\mathrm{ca} .600{ }^{\circ} \mathrm{C}\right)$. Furthermore, the $\mathrm{g}-\mathrm{C}_{3} \mathrm{~N}_{4} @ \mathrm{~N}-\mathrm{G}$ showed a lower thermo stability over $300 \sim 600{ }^{\circ} \mathrm{C}$ due, most probably, to the increased defects associated with the deposition of g$\mathrm{C}_{3} \mathrm{~N}_{4}$ onto the N-G sheets, in a good agreement with the Raman results. 
To evaluate the chemical structure, we further performed X-ray photoelectron spectroscopic (XPS) analyses. Fig. 2(d) shows an XPS survey spectrum for $\mathrm{g}-\mathrm{C}_{3} \mathrm{~N}_{4} @ \mathrm{~N}-\mathrm{G}$. The corresponding XPS spectra for $g-C_{3} N_{4}$ and $N-G$ were given in Fig. S1. All of the XPS spectra show a pronounced $\mathrm{C}$ 1s peak, along with a $\mathrm{N} 1 \mathrm{~s}$ and $\mathrm{O} 1$ s peak. As we shall see later, the $\mathrm{O} 1 \mathrm{~s}$ peak arises mainly from physically adsorbed oxygen since graphitic carbon is known to be susceptible to oxygen adsorption even at pressures as low as $10^{-8}$ to $10^{-10}$ Torr [28], typical for the XPS measurements. The strong oxygen adsorption capacity offers an additional advantage for ORR electrocatalysis. As can be seen in Fig. $\mathrm{S} 1(\mathrm{~b})$, the $\mathrm{C} 1 \mathrm{~s}$ spectrum of $\mathrm{g}-\mathrm{C}_{3} \mathrm{~N}_{4}$ shows two main carbon component peaks at the binding energies of 284.6 and $288.0 \mathrm{eV}$, corresponding to $\mathrm{C}-\mathrm{N}-$ $\mathrm{C}$ and $\mathrm{C}-(\mathrm{N}) 3$, respectively [27]. On the other hand, N1s spectrum of $\mathrm{g}-\mathrm{C}_{3} \mathrm{~N}_{4}$ given in Fig. S1(c) shows two peaks at around 398.8 and $401.0 \mathrm{eV}$ corresponding to pyridinic-N and graphitic-N, respectively, in consistent with the molecular structure of $\mathrm{g}-\mathrm{C}_{3} \mathrm{~N}_{4}$ [29]. The high resolution N1s spectrum of N-G given in Fig. S1(f) was deconvoluted into three peaks at 398.6, 400.5 and 405.7 $\mathrm{eV}$ corresponding to the pyridinic- $\mathrm{N}$, pyrrolic- $\mathrm{N}$ and $\mathrm{N}$-oxides, respectively $[26,30]$ while the corresponding C1s spectrum in Fig. S1(e) could be fitted into C=C, C-C and C-N with no Ocontaining peak component, indicating no oxygen-bonded carbon (vide supra). The $\mathrm{C} 1 \mathrm{~s}$ spectrum of g- $\mathrm{C}_{3} \mathrm{~N}_{4} @ \mathrm{~N}-\mathrm{G}$ given in Fig. 2(e) could also be deconvoluted into a dominated peak for $\mathrm{sp}^{2}-\mathrm{C}$ at $284.6 \mathrm{eV}$, along with the other two weaker peaks associated with $\mathrm{sp}^{3}-\mathrm{C}$ at $285.6 \mathrm{eV}$, $\mathrm{C}-\mathrm{N}$ at $286.0 \mathrm{eV}$, respectively, with no O-containing peak component, indicating once again that physical adsorption is responsible for the $\mathrm{O}$ 1s peak seen in Fig. 2(d). The N1s spectrum of $\mathrm{g}$ $\mathrm{C}_{3} \mathrm{~N}_{4} @ \mathrm{~N}-\mathrm{G}$ shown in Fig. 2(f) was fitted to pyridinic-N at $\sim 398.6 \mathrm{eV}$, pyrrolic- $\mathrm{N}$ at $\sim 400.6 \mathrm{eV}$, graphitic-N at $\sim 401.0 \mathrm{eV}$ and N-oxides at $\sim 405.7 \mathrm{eV}$, respectively [31]. Overall, the XPS spectra of $\mathrm{g}-\mathrm{C}_{3} \mathrm{~N}_{4} @ \mathrm{~N}-\mathrm{G}$ exhibited the characteristic peaks of both $\mathrm{g}-\mathrm{C}_{3} \mathrm{~N}_{4}$ and $\mathrm{N}-\mathrm{G}$, indicating an 
intimate combination of the $\mathrm{N}-\mathrm{G}$ with $\mathrm{g}-\mathrm{C}_{3} \mathrm{~N}_{4}$ by ball milling, as also revealed by the TEM examination (cf. Fig. 1(c)).

The incorporation of $\mathrm{N}-\mathrm{G}$ into $\mathrm{g}-\mathrm{C}_{3} \mathrm{~N}_{4}$ or vice versa could increase the electrical conductivity and nitrogen content (Fig. 2(d), 8.9\% of $\mathrm{g}-\mathrm{C}_{3} \mathrm{~N}_{4} @ \mathrm{~N}-\mathrm{G}$ vs. $4.0 \%$ for N-G. Fig. S1(d)) of the catalyst, leading to improved ORR electrocatalysis. The ORR electrocatalytic activity of g$\mathrm{C}_{3} \mathrm{~N}_{4} @ \mathrm{~N}-\mathrm{G}$ was tested by conventional three-electrode cyclic voltammetry $(\mathrm{CV})$ in $\mathrm{O}_{2}$ and $\mathrm{N}_{2}$ saturated 0.1M KOH aqueous solutions, respectively. Fig. S2(a) shows that a characteristic ORR peak starting at about $-0.10 \mathrm{~V}$ was observed for oxygen reduction on the $\mathrm{g}-\mathrm{C}_{3} \mathrm{~N}_{4} @ \mathrm{~N}-\mathrm{G}$ electrode in the $\mathrm{O}_{2}$ saturated $0.1 \mathrm{M} \mathrm{KOH}$, but not in the $\mathrm{N}_{2}$ saturated $0.1 \mathrm{M} \mathrm{KOH}$. For comparison, the $\mathrm{CV}$ curves of $g-\mathrm{C}_{3} \mathrm{~N}_{4}$ and $\mathrm{N}-\mathrm{G}$ were shown in Figs. 3(a) and S2(b), along with the corresponding curve for $\mathrm{g}-\mathrm{C}_{3} \mathrm{~N}_{4} @ \mathrm{~N}-\mathrm{G}$. As can be seen, the peak intensity of $\mathrm{g}-\mathrm{C}_{3} \mathrm{~N}_{4} @ \mathrm{~N}-\mathrm{G}$, with a more positive onset potential, is much stronger than those of $\mathrm{N}-\mathrm{G}$ and $\mathrm{g}-\mathrm{C}_{3} \mathrm{~N}_{4}$, indicating a more effective ORR process on the $\mathrm{g}-\mathrm{C}_{3} \mathrm{~N}_{4} @ \mathrm{~N}-\mathrm{G}$ electrode. A series of linear sweep voltammograms (LSVs) for $\mathrm{g}-\mathrm{C}_{3} \mathrm{~N}_{4}, \mathrm{~N}-\mathrm{G}$ and $\mathrm{g}-\mathrm{C}_{3} \mathrm{~N}_{4} @ \mathrm{~N}-\mathrm{G}$ were measured on a rotating disk electrode (RDE) from 400 to $1600 \mathrm{rpm}$, showing an typically increased current with increasing rotation speeds (Fig. 3(b)). Fig. 3(b) shows an increased ORR onset potential and enhanced limited current density in the order of $\mathrm{g}-\mathrm{C}_{3} \mathrm{~N}_{4}<\mathrm{N}-\mathrm{G}<\mathrm{g}-\mathrm{C}_{3} \mathrm{~N}_{4} @ \mathrm{~N}-\mathrm{G}$ in good agreement with the $\mathrm{CV}$ results, indicating a synergistic effect for $\mathrm{g}-\mathrm{C}_{3} \mathrm{~N}_{4} @ \mathrm{~N}-\mathrm{G}$ as the ORR catalyst. Due to the low quality of the N-G produced from the GO precursor with respected to those produced by chemical vapor deposition (CVD) $[4,33,34]$, relatively poor electrocatalytic performance was observed for the N-G in Figure 3b.

To better investigate the kinetics of ORR, we used rotation ring-disk electrode (RRDE) to evaluate ORR performance of the $\mathrm{g}-\mathrm{C}_{3} \mathrm{~N}_{4} @ \mathrm{~N}-\mathrm{G}$. From Fig. 3(c), the electron transfer number was calculated to be about $4.0[2,4,32]$, indicating a four-electron ORR process. In addition, the 
transferred electron numbers per $\mathrm{O}_{2}$ were also determined by the Koutecky-Levich equation [32], as shown in the supporting information. From the K-L plots shown in Figs. 3(d) and S2(d \& e), the electron transfer number (n) of $\mathrm{g}-\mathrm{C}_{3} \mathrm{~N}_{4}, \mathrm{~N}-\mathrm{G}$ and $\mathrm{g}-\mathrm{C}_{3} \mathrm{~N}_{4} @ \mathrm{~N}-\mathrm{G}$ at different potential were presented in Fig. 3(e). As can be seen, $\mathrm{g}-\mathrm{C}_{3} \mathrm{~N}_{4} @ \mathrm{~N}-\mathrm{G}$ showed $\mathrm{n}=4.0$, which is in good agreement with the corresponding value estimated from RRDE, whereas the N-G and $g-\mathrm{C}_{3} \mathrm{~N}_{4}$ exhibited $n=3.1$ and 2.0, respectively. Clearly, the combination of $g-C_{3} N_{4}$ and $N-G$ has greatly enhanced the oxygen reduction process on the $\mathrm{g}-\mathrm{C}_{3} \mathrm{~N}_{4} @ \mathrm{~N}-\mathrm{G}$ electrode.

As shown in Fig. S2(c), the ORR onset potentials of $\mathrm{g}-\mathrm{C}_{3} \mathrm{~N}_{4}, \mathrm{~N}-\mathrm{G}$, and $\mathrm{g}-\mathrm{C}_{3} \mathrm{~N}_{4} @ \mathrm{~N}-\mathrm{G}$ are about $-0.31 \mathrm{~V},-0.15 \mathrm{~V}$ and $-0.02 \mathrm{~V}$ (E vs. SCE), respectively. Similarly, the ORR half-wave potential $\left(\mathrm{E}_{1 / 2}\right)$ of $\mathrm{g}-\mathrm{C}_{3} \mathrm{~N}_{4} @ \mathrm{~N}-\mathrm{G}$ is about $-0.22 \mathrm{~V}$ (E vs. SCE), which is much better than that of $\mathrm{g}-$ $\mathrm{C}_{3} \mathrm{~N}_{4}\left(\mathrm{E}_{1 / 2} \approx-0.44 \mathrm{~V}\right)$ and $\mathrm{N}-\mathrm{G}\left(\mathrm{E}_{1 / 2} \approx-0.40 \mathrm{~V}\right)$. Fig. $\mathrm{S} 2(\mathrm{c})$ shows an ORR catalytic activity comparable to the commercial Pt/C catalyst for $\mathrm{g}-\mathrm{C}_{3} \mathrm{~N}_{4} @ \mathrm{~N}-\mathrm{G}$. In a control experiment, the g$\mathrm{C}_{3} \mathrm{~N}_{4}$ and $\mathrm{N}-\mathrm{G}$ mixture was also prepared by simply stirring mixing for $24 \mathrm{~h}$ without ball milling, which was demonstrated to show an inferior ORR performance than $\mathrm{g}-\mathrm{C}_{3} \mathrm{~N}_{4} @ \mathrm{~N}-\mathrm{G}$ (Fig. S2(c)), indicating that ball milling played an important role in improving the catalytic activity.

The $\mathrm{g}-\mathrm{C}_{3} \mathrm{~N}_{4} @ \mathrm{~N}-\mathrm{G}$ electrode was further subjected to stability assessment and tested for possible methanol crossover effect. As shown in Fig. 4(a), the original cathodic ORR current of g- $\mathrm{C}_{3} \mathrm{~N}_{4} @ \mathrm{~N}-\mathrm{G}$ at $-0.3 \mathrm{~V}$ did not show a significant change after the sequential addition of methanol into the electrolyte solution (a total methanol concentration of $3 \mathrm{M}$ ), suggesting that g$\mathrm{C}_{3} \mathrm{~N}_{4} @ \mathrm{~N}-\mathrm{G}$ is free from the methanol crossover effect. In contrast, the commercial Pt/C showed an immediate change upon the addition of methanol, indicating a conversion of the dominated oxygen reduction to the methanol oxidation reaction, which can be considered as a poisoning of the catalyst. The durability of $\mathrm{g}-\mathrm{C}_{3} \mathrm{~N}_{4} @ \mathrm{~N}-\mathrm{G}$ was evaluated by the chronoamperometric response at -0.3 V. As shown in Fig. 4(b), the metal-free $\mathrm{g}-\mathrm{C}_{3} \mathrm{~N}_{4} @ \mathrm{~N}-\mathrm{G}$ catalyst exhibited high stability 
with a very slow attenuation and a high current retention (96.3\%) even after $30000 \mathrm{~s}$, showing a much better durability than that of the commercial Pt/C catalyst. To the best of our knowledge, g- $\mathrm{C}_{3} \mathrm{~N}_{4} @ \mathrm{~N}-\mathrm{G}$ showed the best performance among the carbon nitride based electrocatalysts for oxygen reduction, as seen in Table $\mathrm{S} 1$.

\section{Conclusions}

By ball-milling $\mathrm{g}-\mathrm{C}_{3} \mathrm{~N}_{4}$ generated by pyrolysis of cyanamide under a flow of argon gas and $\mathrm{N}$-doped graphene from the modified Hummer's method, we have produced a new class of lowcost, metal-free ORR catalysts with $\mathrm{g}-\mathrm{C}_{3} \mathrm{~N}_{4}$ intimately supported by $\mathrm{N}-\mathrm{G}$ sheets. The resultant $\mathrm{g}-$ $\mathrm{C}_{3} \mathrm{~N}_{4} @ \mathrm{~N}-\mathrm{G}$ exhibited excellent catalytic activity towards oxygen reduction, comparable to commercial $\mathrm{Pt} / \mathrm{C}$ catalyst, with an onset potential at about $-0.02 \mathrm{~V}$ (E vs. SCE) and half-wave potential at about $-0.22 \mathrm{~V}$ (E vs. SCE). The superb ORR performance observed for the $\mathrm{g}$ $\mathrm{C}_{3} \mathrm{~N}_{4} @ \mathrm{~N}-\mathrm{G}$ could be attributed to the synergetic effect arising from the ball-milling-induced intimate combination of nitrogen-rich $\mathrm{g}-\mathrm{C}_{3} \mathrm{~N}_{4}$ and $\mathrm{N}-\mathrm{G}$ with a good conductivity. This work represents an important step forward in the scalable production of advanced high-performance, low-cost, metal-free catalysts by ball milling techniques.

\section{Conflict of interest}

There is no conflict of interest among the authors.

\section{Acknowledgments}

L.D. is grateful for financial support from NSF (CMMI-1400274, CMMI-1266295, AIR-IIP1343270, DMR 1106160), DAGSI (RQ20-CWRU-13-4), DOD-Army (W911NF-11-1-0209), and Z.W. thanks CSC and UBCT. 


\section{References}

1. Q. Li, R. Cao, J. Cho, G. Wu Adv. Energy Mater. 4 (2014) 1301415.

2. $\quad$ K. Gong, F. Du, Z. Xia, M. Durstock, L. Dai, Science 323 (2009) 760-764.

3. D. Yu, Q. Zhang, L. Dai, J. Am. Chem. Soc. 132 (2010) 15127-15129.

4. L. Qu, Y. Liu, J.-B. Baek, L. Dai, ACS Nano 4 (2010) 1321-1326.

5. S. Wang, L. Zhang, Z. Xia, A. Roy, D. W. Chang, J.-B. Baek, L. Dai Angew. Chem. Int. Ed. 51 (2012) 4209-4212.

6. D. Yu, Y. Xue, L. Dai J. Phys. Chem. Lett. 3 (2012) 2863-2870.

7. A. Y. Liu, M. L. Cohen Science 245 (1989) 841-842.

8. S. M. Lyth, Y. Nabae, S. Moriya, S. Kuroki, M.-a. Kakimoto, J.-J. Ozaki, S. Miyata J. Phys. Chem. C 113 (2009) 20148-20151.

9. X. Wang, K. Maeda, A. Thomas, K. Takanabe, G. Xin, J. M. Carlsson, K. Domen, M. Antonietti Nat. Mater. 8 (2009) 76-80.

10. F. Goettmann, A. Thomas, M. Antonietti, Angew. Chem. Int. Ed. 46 (2007) 2717-2720.

11. F. Goettmann, A. Fischer, M. Antonietti, A. Thomas New J. Chem. 31 (2007) 1455-1460.

12. S. M. Lyth, Y. Nabae, N. M. Islam, S. Kuroki, M. Kakimoto, S. Miyata J. Electrochem. Soc. 158 (2011) B194-B201.

13. Y. Sun, C. Li, Y. Xu, H. Bai, Z. Yao, G. Shi Chem. Commun. 46 (2010) 4740-4742.

14. $\quad$ S. B. Yang, X. L. Feng, X. C. Wang, K. Mullen Angew. Chem. Int. Ed. 50 (2011) 53395343.

15. K. Qiu, Z. X. Guo J. Mater. Chem. A 2 (2014) 3209-3215.

16. Y. Zheng, Y. Jiao, M. Jaroniec, Y. Jin, S. Z. Qiao Small 8 (2012) 3550-3566.

17. Y. Zheng, J. Liu, J. Liang, M. Jaroniec, S. Z. Qiao Energy \& Environ. Sci. 5 (2012) 6717-6731. 
18. Y. Zheng, Y. Jiao, J. Chen, J. Liu, J. Liang, A. Du, W. Zhang, Z. Zhu, S. C. Smith, M. Jaroniec, G. Q. Lu, S. Z. Qiao, J. Am. Chem. Soc. 133 (2011) 20116-20119.

19. J. Liang, Y. Zheng, J. Chen, J. Liu, D. Hulicova-Jurcakova, M. Jaroniec, S. Z. Qiao, Angew. Chem. Int. Ed. 51 (2012) 3892-3896.

20. I.-Y. Jeon, H.-J. Choi, M. Choi, J.-M. Seo, S.-M. Jung, M.-J. Kim, S. Zhang, L. Zhang, Z. Xia, L. Dai, N. Park, J.-B. Baek Sci. Rep. 3 (2012) 1810.

21. I.-Y. Jeon, Y.-R. Shin, G.-J. Sohn, H.-J. Choi, S.-Y. Bae, J. Mahmood, S.-M. Jung, J.-M. Seo, M.-J. Kim, D. Wook Chang, L. Dai, J.-B. Baek Proc. Natl. Acad. Sci. 109 (2012) 5588-5593.

22. I.-Y. Jeon, H.-J. Choi, S.-M. Jung, J.-M. Seo, M.-J. Kim, L. Dai, J.-B. Baek J. Am. Chem. Soc. 135 (2012) 1386-1393.

23. I.-Y. Jeon, S. Zhang, L. Zhang, H.-J. Choi, J.-M. Seo, Z. Xia, L. Dai, J.-B. Baek Adv. Mater. 25 (2013) 6138-6145.

24. W. S. Hummers, R. E. Offeman J. Am. Chem. Soc. 80 (1958) 1339-1339.

25. Y. H. Xue, H. Chen, D. S. Yu, S. Y. Wang, M. Yardeni, Q. B. Dai, M. M. Guo, Y. Liu, F. Lu, J. Qu, L. M. Dai Chem. Commun. 47 (2011)11689-11691.

26. Y. Xue, J. Liu, H. Chen, R. Wang, D. Li, J. Qu, L. Dai Angew. Chem. Int. Ed. 51 (2012) 12124-12127.

27. F. Dong, L. Wu, Y. Sun, M. Fu, Z. Wu, S. C. Lee J. Mater. Chem. 21 (2011) 1517115174.

28. P. G. Collins, K. Bradley, M. Ishigami, A. Zettl Science 287 (2000) 1801-1804.

29. S. Barman, M. Sadhukhan J. Mater. Chem. 22 (2012) 21832-21837.

30. I.-Y. Jeon, D. Yu, S.-Y. Bae, H.-J. Choi, D. W. Chang, L. Dai, J.-B. Baek Chem. Mater. 23 (2011) 3987-3992.

31. W. Ding, Z. Wei, S. Chen, X. Qi, T. Yang, J. Hu, D. Wang, L.-J. Wan, S. F. Alvi, L. Li, Angew. Chem. Int. Ed. 52 (2013) 11755-11759.

32. S. Wang, D. Yu, L. Dai, D. W. Chang, J.-B. Baek ACS Nano, 5 (2011) 6202-6209.

33. M. Vikkisk, I. Kruusenberg, U. Joost, E. Shulga, I. Kink, K. Tammeveski Appl. Catal. B: Environ. 147 (2014) 369-376.

34. S. Ratso, I. Kruusenberg, M. Vikkisk, U. Joost, E. Shulga, I. Kink, T. Kallio, K. Tammeveski Carbon 73 (2014) 361-370. 

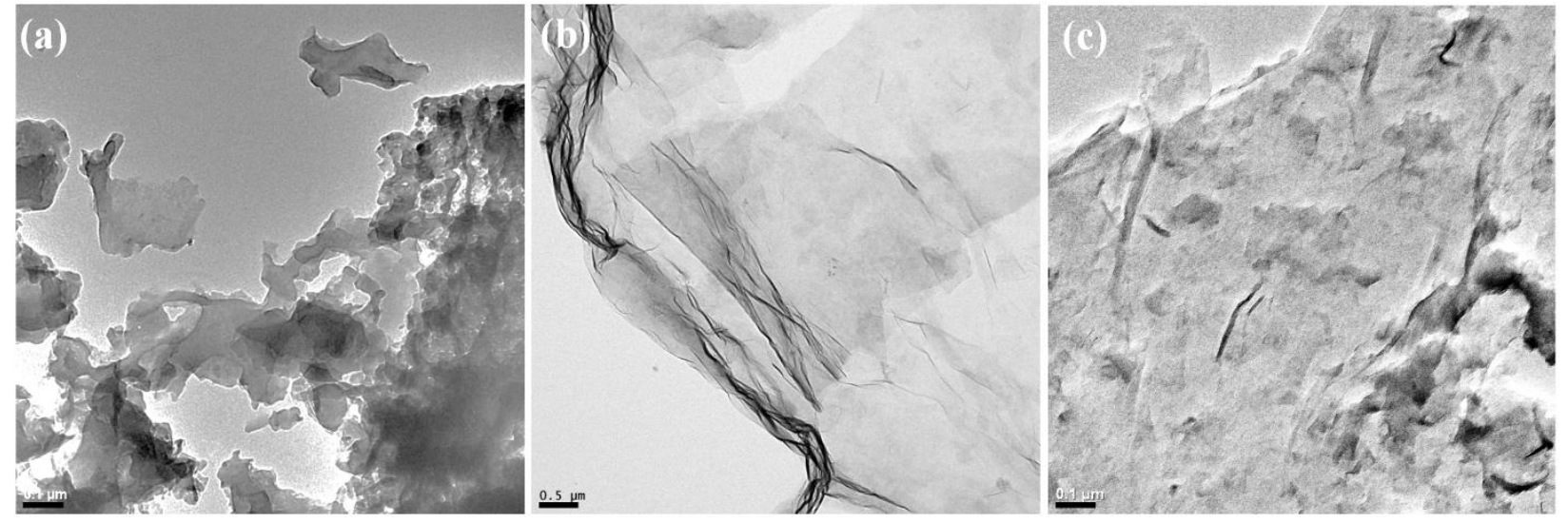

Fig. 1. TEM images of (a) $\mathrm{C}_{3} \mathrm{~N}_{4}$ (scale bar: $100 \mathrm{~nm}$ ), (b) N-G (scale bar: $500 \mathrm{~nm}$ ), and (c) $\mathrm{C}_{3} \mathrm{~N}_{4} @ \mathrm{~N}-\mathrm{G}$ (scale bar: $100 \mathrm{~nm}$ ). 

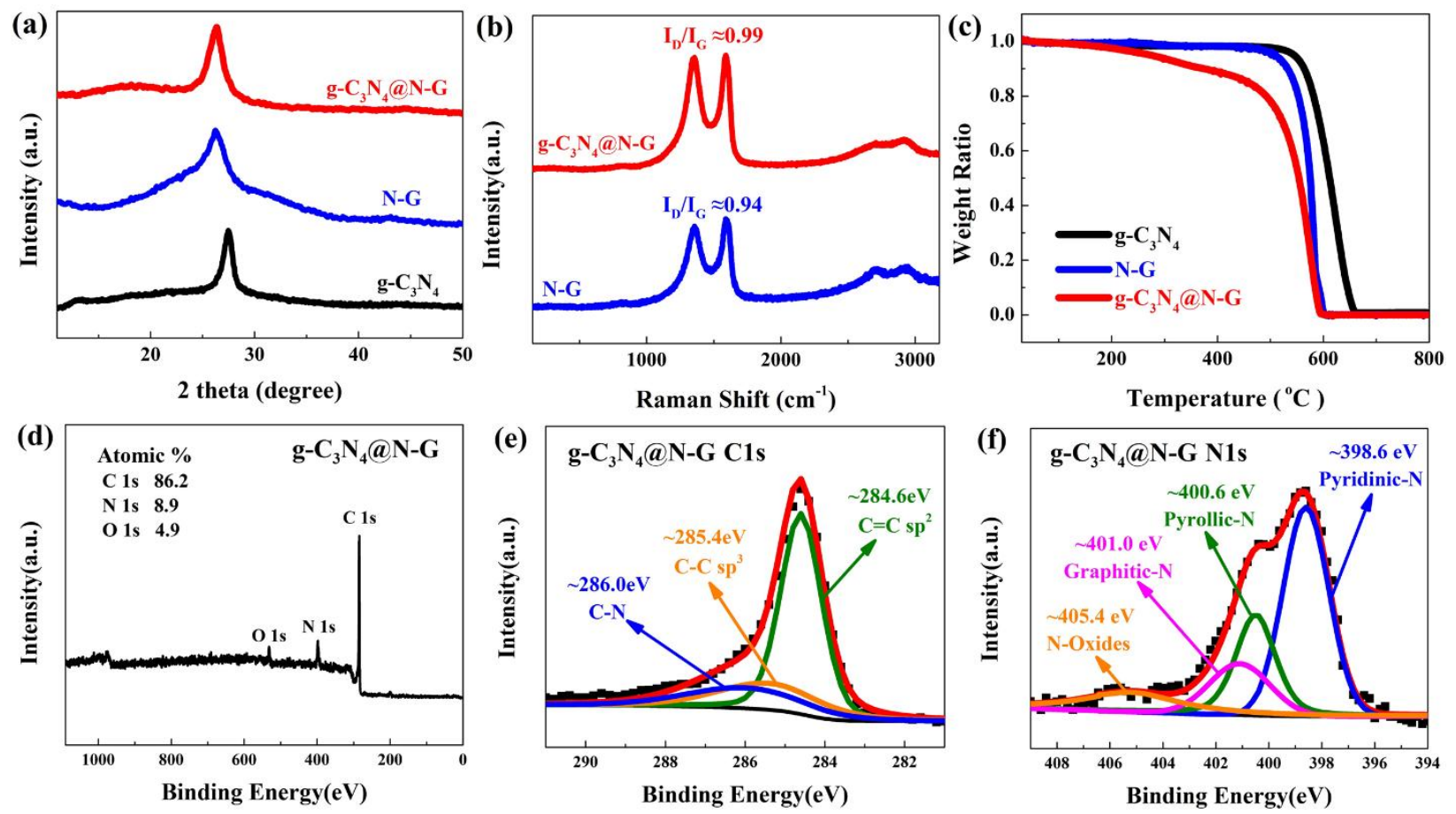

Fig. 2. (a). XRD patterns of $g-C_{3} N_{4}, N-G$ and g- $C_{3} N_{4} @ N-G$, (b) Raman spectra of N-G and g- $C_{3} N_{4} @ N-G$, (c) TGA curves of g- $\mathrm{C}_{3} \mathrm{~N}_{4}, \mathrm{~N}-\mathrm{G}$ and $\mathrm{g}_{-} \mathrm{C}_{3} \mathrm{~N}_{4} @ \mathrm{~N}-\mathrm{G}$ under air atmosphere, (d) XPS survey spectrum of g$\mathrm{C}_{3} \mathrm{~N}_{4} @ \mathrm{~N}-\mathrm{G}$, (e) Curve-fitted high resolution XPS C1s spectrum of g- $\mathrm{C}_{3} \mathrm{~N}_{4} @ \mathrm{~N}-\mathrm{G}$, and (f) Curve-fitted high resolution XPS N1s spectrum of $\mathrm{C}_{3} \mathrm{~N}_{4} @ \mathrm{~N}-\mathrm{G}$. 

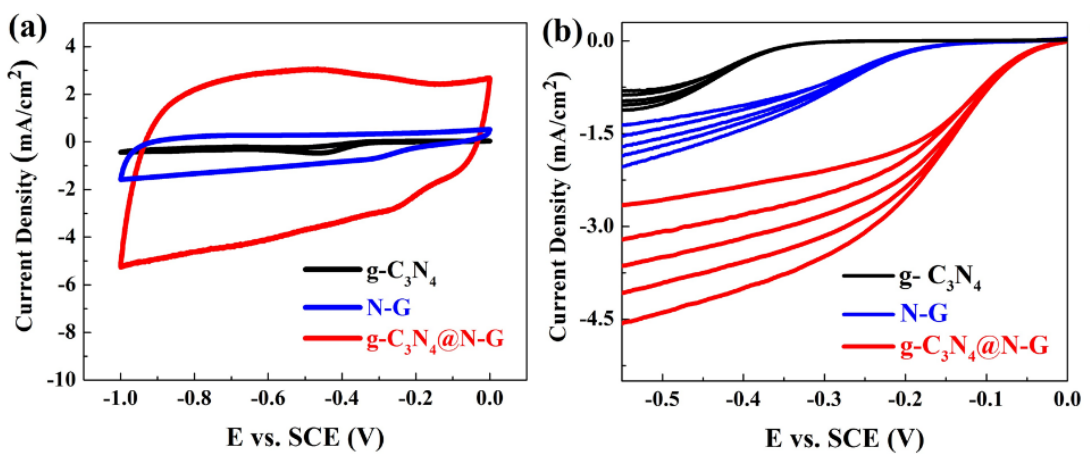
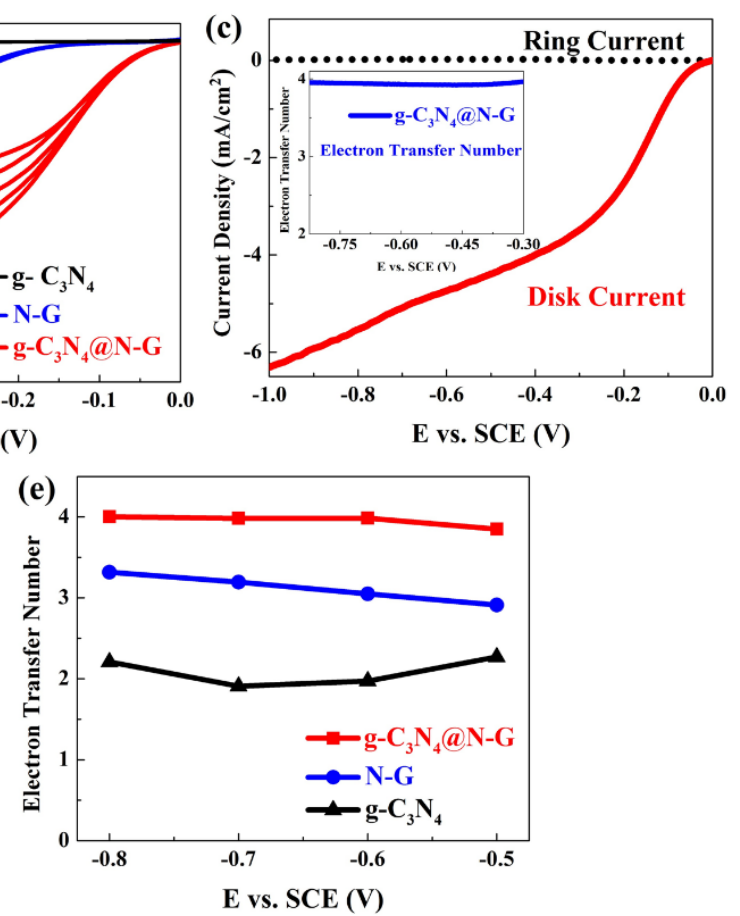

Fig. 3. Catalytic activity towards electrochemical reduction of oxygen in $0.1 \mathrm{M} \mathrm{O}_{2}$-saturated $\mathrm{KOH}$ aqueous solution at room temperature. (a) Cyclic voltammetry $(\mathrm{CVs})$ of g- $\mathrm{C}_{3} \mathrm{~N}_{4}, \mathrm{~N}-\mathrm{G}$ and g- $\mathrm{C}_{3} \mathrm{~N}_{4} @ \mathrm{~N}-\mathrm{G}$ obtained at a sweep rate of $50 \mathrm{mV} \mathrm{s}^{-1}$, (b) Comparison of linear sweep voltammograms (LSVs) of g$\mathrm{C}_{3} \mathrm{~N}_{4}, \mathrm{~N}-\mathrm{G}$ and g- $\mathrm{C}_{3} \mathrm{~N}_{4} @ \mathrm{~N}-\mathrm{G}$ at different rotating speed $(400 \mathrm{rpm}, 600 \mathrm{rpm}, 900 \mathrm{rpm}, 1200 \mathrm{rpm}$ and 1600 $\mathrm{rpm}$ ) at a sweep rate of $5 \mathrm{mV} \mathrm{s}^{-1}$, (c) LSVs of $\mathrm{g}-\mathrm{C}_{3} \mathrm{~N}_{4} @ \mathrm{~N}-\mathrm{G}$ on the RRDE at $1600 \mathrm{rpm}$. Insert shows the electron transfer number of $\mathrm{g}-\mathrm{C}_{3} \mathrm{~N}_{4} @ \mathrm{~N}-\mathrm{G}$ estimated from the ring and disk currents, (d) Koutecky-Levich plot for g- $\mathrm{C}_{3} \mathrm{~N}_{4} @ \mathrm{~N}-\mathrm{G}$ obtained from LSVs in (b), and (e) Electron transfer number of $\mathrm{g}_{-} \mathrm{C}_{3} \mathrm{~N}_{4}, \mathrm{~N}-\mathrm{G}$ and g$\mathrm{C}_{3} \mathrm{~N}_{4} @ \mathrm{~N}-\mathrm{G}$ calculated from Koutecky-Levich equation. 

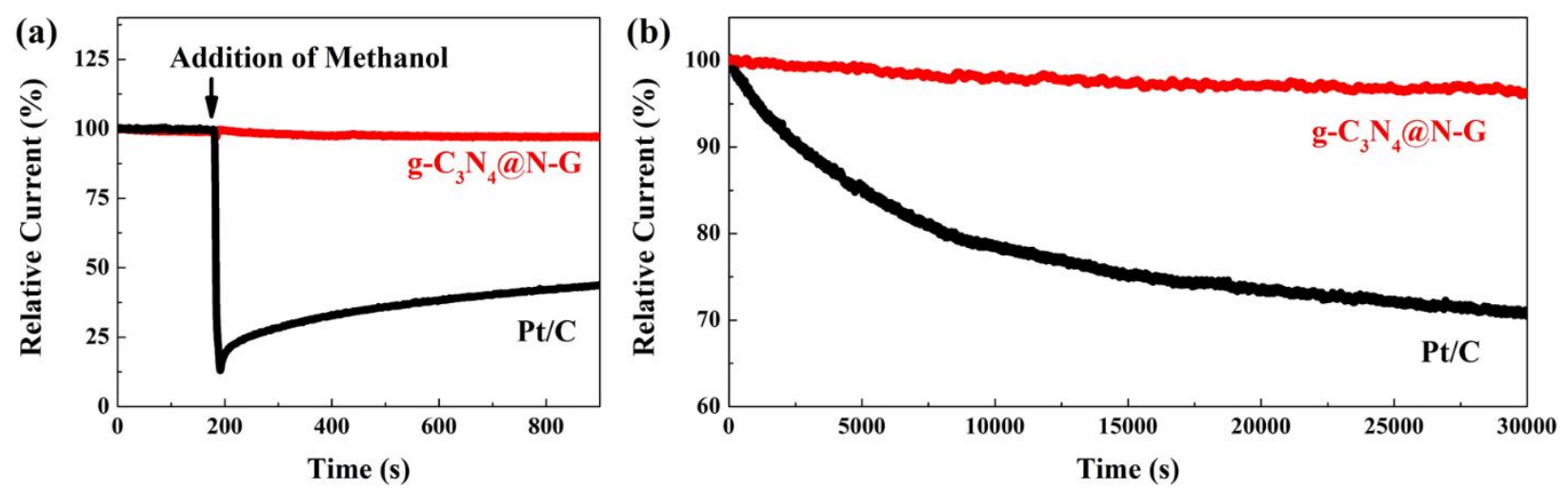

Fig. 4. (a) The current-time (i-t) chronoamperometric responses for ORR at the $g-\mathrm{C}_{3} \mathrm{~N}_{4} @ \mathrm{~N}-\mathrm{G}$ and $\mathrm{Pt} / \mathrm{C}$ electrode in $0.1 \mathrm{M} \mathrm{O}_{2}$-saturated $\mathrm{KOH}$ aqueous solution at $-0.3 \mathrm{~V}$ versus $\mathrm{SCE}$, and $3.0 \mathrm{M}$ methanol was added at around $200 \mathrm{~s}$, (b) Durability curves (i-t) of $\mathrm{g}-\mathrm{C}_{3} \mathrm{~N}_{4} @ \mathrm{~N}-\mathrm{G}$ and $\mathrm{Pt} / \mathrm{C}$ obtained in at $-0.3 \mathrm{~V}$ versus SCE at a rotation rate of $1000 \mathrm{rpm}$. 